\title{
Debrominated and methoxylated polybrominated diphenyl ether metabolites in rainbow trout (Oncorhynchus mykiss) after exposure to decabromodiphenyl ether
}

\author{
Chenglian Feng, Yiping Xu, Yue He, Qian Luo, Jinmiao Zha, Zijian Wang* \\ State Key Laboratory of Environmental Aquatic Chemistry, Research Center for Eco-Environmental Sciences, \\ Chinese Academy of Sciences, Beijing 100085, China. E-mail: fengchenglian@163.com
}

Received 14 December 2009; revised 12 March 2010; accepted 08 April 2010

\begin{abstract}
Decabromodiphenyl ether (BDE209) is the primary component in a commonly used flame retardant. Previous studies had proved that BDE209 itself was not toxic, while its metabolites including debrominated diphenyl ethers (De-BDEs) and methoxylated brominated diphenyl ethers (MeO-BDEs) posed a potential threat to organisms. Many studies had indicated that BDE209 could metabolize quickly in mammals, but lacking in the basic data about the metabolism of BDE209 in fish. In the present study, two replicate treatment groups of rainbow trout (Oncorhynchus mykiss) were exposed to BDE209 via a single intraperitoneal injection approximately $100 \mathrm{and} 500 \mathrm{ng} / \mathrm{g}$, respectively. Muscle, liver and blood samples were collected to analyze the specific metabolites on day 1 and day 28 post injection. The highest concentration of BDE209 was detected in muscle tissues, from $796.1 \mathrm{ng} / \mathrm{g}$ wet weight (day 1) to $687.1 \mathrm{ng} / \mathrm{g}$ wet weight (day 28 ) in high dose group, suggesting that BDE209 could accumulate slightly in muscle tissues. However, BDE209 was not detected in the blood for all treatments. Most congeners of De-BDEs were found in muscle and liver tissues, with the highest concentration in the liver. The main De-BDEs were nona-, octa-, hepta- and penta-De-BDEs. A total of seven MeO-BDE metabolites were observed among different fish tissues. Blood had the highest contribution of the MeO-BDE metabolites. Each MeO-BDE congener increased over the 28 days. These results in contrast to other studies suggested possible species-specific differences in metabolic abilities.
\end{abstract}

Key words: decabromodiphenyl ether (BDE209); methoxylated brominated diphenyl ethers (MeO-BDEs); debrominated diphenyl ethers (De-BDEs); rainbow trout

DOI: $10.1016 /$ S1001-0742(09)60271-0

\section{Introduction}

Polybrominated diphenyl ethers (PBDEs) are widely used as flame retardants (BFRs), which are ubiquitous environmental contaminants found in both abiotic and biotic environmental samples (Mazdai et al., 2003; Jin et al., 2008; Gao et al., 2009). Although the toxicity of PBDEs is not well understood, these compounds may be neurotoxic, thyrotoxic, estrogenic, and carcinogenic (Siddiqi et al., 2003). Of the three main commercial PBDE mixtures (penta-, octa- and deca-BDE) in use, the pentaBDE and octa-BDE mixtures are currently being phased out in Europe, whereas commercial deca-BDE, which is the principal component in flame retardants, is restricted to use in electronic devices in the European Union (de Wit, 2002; SFT, 2009). BDE209 has been measured and reported in almost all natural media including air, sediments, biota, biosolids, and house dust (Strandberg et al., 2001; Stapleton et al., 2005; Chen et al., 2006; Guo et al., 2008; Shi et al., 2009). Because this compound is very hydrophobic $\left(\log K_{\mathrm{ow}} \approx 10\right)$, it has been suggested that BDE209

\footnotetext{
* Corresponding author. E-mail: wangzj@ rcees.ac.cn
}

has very low bioavailability, although its debromination to more bioavailable metabolites has also been suggested to occur in fish tissues (Stapleton et al., 2004). In the environment, BDE209 is susceptible to degradation via debromination, following exposure to UV light and by organisms (Eriksson et al., 2004; Soderstrom et al., 2004; Gerecke et al., 2005). The extent to which BDE209 is accumulated and metabolized by aquatic biota has become a hotly debated topic in recent years (Shaw et al., 2008). A preliminary study on debromination of BDE209 in caged rainbow trout following dietary exposure showed a slow but measurable uptake of BDE209 followed by the detection of several low brominated PBDEs (Kierkegaard et al., 1999). Similar patterns of octa- and nona-BDE were identified in freshwater fish and crustaceans exposed to BDE209 in wastewater effluent, suggesting that BDE209 debromination may also occur in wild fish in aquatic environment (La Guardia et al., 2007). Other than the debrominated diphenyl ethers (De-BDEs) metabolites, the methoxylated brominated diphenyl ethers (MeO-BDEs) metabolites were also studied among different fish species (Hardy, 2002; Hakk and Letcher, 2003). MeO-BDEs have 
been reported in marine fish, freshwater fish, birds and seals in the Baltic Sea area (Haglund et al., 1997; Olsson et al., 2000). Two tetra-MeO-BDEs were reported from green turtle and marine mammals from the Southern Hemisphere (Vetter, 2001; Vetter et al., 2002). Moreover, MeO-BDE metabolites containing 6-7 bromine atoms also have been shown in rats exposed to BDE209 (Mörck et al., 2003).

The present study was undertaken to investigate and examine the tissue-specific congener patterns of BDE209 and the metabolites in muscle, liver and blood of rainbow trout after 28-day exposure period. A total of $27 \mathrm{BDE}$ congeners, from mono- to deca-BDEs and eight $\mathrm{MeO}-$ BDEs, including $\mathrm{MeO}$-tetra-BDBs and $\mathrm{MeO}$-penta-BDEs were determined. To our knowledge, this is the first study to document the tissue distribution of BDE209 metabolites in rainbow trout after a single intraperitoneal injection. The data could also provide scientific supports to the future research of BDE209 degradation in other animals.

\section{Materials and methods}

\subsection{Standards and reagents}

All solvents used for extraction and clean-up process, including dichloromethane (DCM), hexane and acetone, with high performance liquid chromatography (HPLC) grade were obtained from J. T. Baker (USA). Commercial deca-BDE mixtures (BDE-209: purity $\geqslant 98 \%$ ) used for the exposure experiment were kindly provided by Dalian Institute of Chemical Physics, Chinese Academy of Sciences, China. The following PBDEs and MeO-BDEs standards were obtained from Wellington Laboratories (Ontario, Canada). The BDE mixture standards contain 27 BDE congeners (BDE3, 7, 15, 17, 28, 47, 49, 66, 71, 77, 85, 99, 100, 119, 126, 138, 153, 154, 156, 183, 184, 191, 196, 197, 206, 207, 209). MeO-BDEs mixture standards include four tetra-MeO$\mathrm{BDE}$ congeners and four penta-MeO-BDE congeners. ${ }^{13} \mathrm{C}$-labeled PBDE mixture $\left({ }^{13} \mathrm{C}\right.$-labeled BDE3, 15, 28, 47 , $99,153,154,183,197,207$ and 209) were used to optimize extraction and cleanup procedure for good recovery and sensitivity for BDE congeners. ${ }^{13} \mathrm{C}$-labeled 2,2',4,4'tetrabromo-6-methoxy diphenyl ether (M6MBDE47) and ${ }^{13}$ C-labeled 2,2',4,4',6-pentabromo-6'-methoxy diphenyl ether (M6PMBDE100) were used as recovery surrogates. ${ }^{13}$ C-labeled BDE138 (2,2',3,4,4', $5^{\prime}$-hexabromo diphenyl ether) was used as an internal standard.

\subsection{Fish and exposure}

Juvenile rainbow trout (about four months old), approximately $200 \mathrm{~mm}$ in length, $100 \mathrm{~g}$ in weight, were purchased from local fish farm. Fish were randomly stocked in $250 \mathrm{~L}$ glass tanks including replicated control and two treatment groups. These fish were maintained in aerated de-chlorinated tap water (using an activated carbon filter) at a constant temperature $\left(15 \pm 2^{\circ} \mathrm{C}\right)$, which was close to their optimal temperature range in the natural environment, with a photoperiod of $16 \mathrm{hr}: 8 \mathrm{hr}$ (light:dark). Fish were acclimated for a week prior to the beginning of the experiment.

BDE209 was dissolved in corn oil to make the parent BDE209 solution reaching up to $0.25 \mathrm{~g} / \mathrm{L}$. Two treated group and one control group were set up to carry out the experiment. The control group was only injected with corn oil and fed with clean food (Tetra Pond Sticks, Germany). In one treatment group, fish were injected intraperitoneally with $50 \mu \mathrm{L}$ parent BDE209 solution; in the other treatment group, fish were injected the same way with $200 \mu \mathrm{L}$ parent BDE209 solution. Therefore, the initial concentrations of BDE209 of each treated group were 100 or $500 \mathrm{ng} / \mathrm{g}$ fresh weight. During the exposure period (28 days), fish were fed once a week. Also, it must be ensured that the food was consumed within 20-40 sec.

\subsection{Sampling}

Three replicate tissue samples were prepared from the fish randomly sampled from each tank on day 1 and day 28. To avoid contamination from the gastrointestinal tract, the fish were starved for 24-48 hr before sampling. Fish were killed by a blow to the head, fish mass and length were recorded and blood samples were taken directly from the caudal aorta. Blood was collected in centrifuge tube containing sodium heparin as the anticoagulant. The blood samples were immediately separated into plasma and red blood cells by centrifugation $(10,000 \mathrm{r} / \mathrm{min})$ for $15 \mathrm{~min}$ at $4^{\circ} \mathrm{C}$. The viscera of each fish were dissected, and the muscle and liver were separated and weighted. Finally, the muscle, liver and blood samples were stored at $-80^{\circ} \mathrm{C}$ prior to further analysis.

\subsection{Sample pretreatment}

The muscle and liver samples were extracted and cleaned up as described elsewhere (Luo et al., 2007). In brief: the muscle (skin removed) samples were freezedried, and the water content of muscle was determined. Each dried fish muscle was homogenized in a stainless steel blender. About $2 \mathrm{~g}$ of dried fish muscles were mixed with $4 \mathrm{~g}$ of anhydrous sodium sulfate, which was cleaned with DCM and activated at $140^{\circ} \mathrm{C}$ for $24 \mathrm{hr}$ in advance. Meanwhile, each liver sample (ca. $1 \mathrm{~g}$ wet weight/one liver) was homogenized with $4 \mathrm{~g}$ anhydrous sodium sulfate. After spiked with ${ }^{13} \mathrm{C}$-labled $\mathrm{BDE}$ and $\mathrm{MeO}-\mathrm{BDE}$ mixture recovery standards, the muscle and liver samples were extracted with $100 \mathrm{~mL}$ of DCM/acetone $(1: 1, V / V)$ for 24 $\mathrm{hr}$ in Soxhlet extraction system. Then, the sample extracts were concentrated with a rotary evaporator and transferred to a glass bottle with $6 \mathrm{~mL}$ of hexane. The extracts were then treated with concentrated sulfuric acid to remove the bulk of lipids. Afterwards, cleanup was done on a column containing $4 \mathrm{~g}$ anhydrous sodium sulfate, $10 \mathrm{~g}$ of silica gel impregnated with sulfuric acid (30\%) and $2 \mathrm{~g}$ of active silica gel with the order from top to bottom. Hexane (30 $\mathrm{mL}$ ) was used for elution. The eluted solution was loaded on to a column containing $4 \mathrm{~g}$ of anhydrous sodium sulfate and $8 \mathrm{~g}$ of acid alumina. The column was eluted with $30 \mathrm{~mL}$ of hexane/DCM $(7: 3, \mathrm{~V} / \mathrm{V})$ that was collected and concentrated under gentle nitrogen evaporation apparatus at room temperature. The sample was dissolved in $100 \mu \mathrm{L}$ 
of hexane containing ${ }^{13} \mathrm{C}$-labeled BDE138 at $500 \mu \mathrm{g} / \mathrm{L}$.

Previously reported methods (Hovander et al., 2000; Qiu et al., 2007) were modified slightly to accommodate the plasma samples in the present study. Each sample was transferred to a centrifuge tube. After spiking with the recovery standards, each sample was denatured with $1 \mathrm{~mL}$ of hydrochloric acid $(6 \mathrm{~mol} / \mathrm{L})$ and $6 \mathrm{~mL}$ of $2-$ propanol. Samples were extracted with $6 \mathrm{~mL}$ of hexane: methyl tert-butyl ether $(1: 1, V / V)$ three times by shaking the tube for more than $5 \mathrm{~min}$ each time. After blowing down the combined extracts, the neutral and phenolic compounds in the extract were separated by partitioning between hexane and potassium hydroxide $(0.5 \mathrm{~mol} / \mathrm{L}$ in $50 \%$ ethanol). The organic phase was extracted by 3 $\mathrm{mL}$ of hexane for three times, and the organic phase was combined. After each step, the vortex process was conducted necessarily. Then, the extracted solution were cleaned up by a column containing $8 \mathrm{~g}$ of anhydrous sodium sulfate, $8 \mathrm{~g}$ of silica gel impregnated with sulfuric acid (30\%), $1 \mathrm{~g}$ of active silica gel and $8 \mathrm{~g}$ of acid alumina with the order from top to bottom. Hexane $(10 \mathrm{~mL})$ was first used for elution, with the elution being retarded. Then, the column was eluted with $20 \mathrm{~mL}$ hexane/DCM (7:3, $V / V)$, and the elution was collected and concentrated under gentle nitrogen evaporation apparatus at room temperature. The sample was also dissolved in $100 \mu \mathrm{L}$ of hexane containing ${ }^{13} \mathrm{C}$-labeled BDE138 at $500 \mu \mathrm{g} / \mathrm{L}$. To prevent photo-degradation, during the entire process the samples remained wrapped with aluminum foil. All the samples (muscle, liver and blood) were concentrated in Agilent vials and stored in fridge at $-80^{\circ} \mathrm{C}$ prior to the analysis.

\subsection{Instrumental analysis}

The samples were analyzed with gas chromatography plus mass spectrometry (GC-MS, Agilent 6890GC-5975B, USA). For the determination of mono- to hexa-BDE congener and MeO-BDEs, a DB-5 MS column (30 $\mathrm{m} \times 0.25$ mm i.d. $\times 0.25 \mu \mathrm{m}$ film thickness) was used. The temperature program was from $110^{\circ} \mathrm{C}$ (hold for $1 \mathrm{~min}$ ) to $240^{\circ} \mathrm{C}$ (hold for $2 \mathrm{~min}$ ) at $15^{\circ} \mathrm{C} / \mathrm{min}$, and then from $240^{\circ} \mathrm{C}$ to $265^{\circ} \mathrm{C}$ (hold for $25 \mathrm{~min}$ ) at $2^{\circ} \mathrm{C} / \mathrm{min}$, using the splitless injection mode during $1 \mathrm{~min}$, with injection volume of $1 \mu \mathrm{L}$. For the determination of hepta- to decaBDEs, a DB-5ms column $(15 \mathrm{~m} \times 0.25 \mathrm{~mm}$ i.d. $\times 0.1 \mu \mathrm{m}$ film thickness) was used. The temperature program was from $150^{\circ} \mathrm{C}$ (hold for $1 \mathrm{~min}$ ) to $325^{\circ} \mathrm{C}$ (hold for $5 \mathrm{~min}$ ) at $17^{\circ} \mathrm{C} / \mathrm{min}$, using the pulsed splitless injection mode until $1.5 \mathrm{~min}$, purge flow $50 \mathrm{~mL} / \mathrm{min}$ at $2.0 \mathrm{~min}$, with injection volume of $1 \mu \mathrm{L}$.

Two different ionization techniques were used: electron ionization (EI) and electron-capture negative ionization (ECNI). For EI, the operating conditions were as follows: ion source temperature at $300^{\circ} \mathrm{C}$, quadrupole temperature at $150^{\circ} \mathrm{C}$, transfer line at $300^{\circ} \mathrm{C}$, scan range at $200-1000$ amu, electron energy is $70 \mathrm{eV}$. The molecular ion peaks $\left([\mathrm{M}]^{+}\right)$or the fragment ions resulting from the loss of $\mathrm{Br}_{2}$ $\left(\left[\mathrm{M}-\mathrm{Br}_{2}\right]^{+}\right)$were selected. For ECNI, helium and methane was used as carrier gas (constant column flow $2.0 \mathrm{~mL} / \mathrm{min}$ ) and reaction gas $(800 \mathrm{~Pa})$, respectively, the multiplier voltage was set to $1250 \mathrm{~V}$. PBDEs were quantified by monitoring ions ${ }_{79} \mathrm{Br}$ and ${ }_{81} \mathrm{Br}$, while PBDE209 were quantified by monitoring ions $\mathrm{m} / \mathrm{z} 486.6$ and 488.5 . The data were acquired using the selected ion monitoring (SIM) mode. All analytes were identified on the basis of their retention time, relative to authentic standards.

\subsection{Quality assurance/quality control}

It should be pointed out that BDE209 has a number of additional analytical difficulties. This compound is not stable at high temperatures in the injector and on the GC column (Eljarrat et al., 2007; Luo et al., 2007). Moreover, the compound is sensitive to the degradation by UV light and strongly adsorbs to any kind of surfaces. The limit of detection (LOD) was defined as the concentration that would result in a signal-to-noise ratio of three, and detection limits for BDE209 was approximately $1.25 \mathrm{ng} / \mathrm{g}$ wet weight. LOD varied from congener to congener based on the amount of sample and the instrument sensitivity. The LODs of BDEs and MeO-BDEs congeners in muscle and liver ranged from $0.05-1.25 \mathrm{ng} / \mathrm{g}$, in blood ranged from $0.25-2.55 \mathrm{ng} / \mathrm{g}$, respectively. Concentrations below the LOD were assumed to be zero in the following discussion. Additionally, one procedural blank was run with every batch of 6-10 samples to assess potential sample contamination, the laboratory blanks demonstrated that the sample analysis was free from contamination. The recovery of the surrogate standards in spiked blanks and fish samples was from $78.9 \%$ to $120.5 \%$, from $72.6 \%$ to $116.8 \%$, respectively, which was in agreement with the USEPA standard.

\section{Results}

\subsection{BDE209 and De-BDEs}

During the exposure time for all the fish samples in the present study, no De-BDEs were detected in the control group, whereas some De-BDEs metabolites were observed in the treatment group. Detailed information about the congener profiles of PBDE in low dose group (LG) and high dose group (HG) are listed in Tables 1 and 2. As for BDE209 itself, the highest concentration was detected in muscle tissues. The BDE209 concentration on day 1 was higher than that on day 28. In liver samples, the BDE209 was much lower than that in muscle samples. Differently, BDE209 was not detectable in blood samples. For one thing, it might be caused by the quick degradation of BDE209 in blood tissue, for another, BDE209 concentrations in blood samples were below the limits of quantification (LOQ). Among the 27 individual BDEs analyzed, a total of 20 BDE congeners were detected. The seven congeners not detected were BDE17, 138, 153, 154, $156,191,196$. On day 1 , a total of 18 BDE congeners were detected, including one mono-BDE (BDE3), two diBDE (BDE7, 15), five tetra-BDE (BDE47, 49, 66, 71, 77), five penta-BDE (BDE85, 99, 100, 119, 126), one heptaBDE (BDE184), one octa-BDE (BDE197), two nona-BDE (BDE206, 207), and deca-BDE (BDE209). No tri-BDEs 
Table 1 BDE209 and De-BDE metabolites in different tissues on day 1 and day 28 in low dose group (LG) (unit: ng/g wet weight)

\begin{tabular}{|c|c|c|c|c|c|c|c|c|c|c|c|c|}
\hline \multirow[t]{3}{*}{$\mathrm{BDE}$} & \multicolumn{6}{|c|}{ Day 1} & \multicolumn{6}{|c|}{ Day 28} \\
\hline & \multicolumn{2}{|c|}{ Muscle } & \multicolumn{2}{|c|}{ Liver } & \multicolumn{2}{|c|}{ Blood } & \multicolumn{2}{|c|}{ Muscle } & \multicolumn{2}{|c|}{ Liver } & \multicolumn{2}{|c|}{ Blood } \\
\hline & Mean & $\mathrm{SD}$ & Mean & SD & Mean & SD & Mean & SD & Mean & SD & Mean & SD \\
\hline BDE3 & - & - & 10.46 & 2.89 & 16.51 & 3.30 & - & - & 35.19 & 7.78 & 125.2 & 68.49 \\
\hline BDE7 & - & - & 10.56 & 2.39 & 13.04 & 1.27 & - & - & 32.63 & 7.48 & 31.11 & 9.76 \\
\hline BDE15 & - & - & 13.41 & 4.12 & 17.67 & 3.48 & - & - & 40.89 & 10.23 & 53.85 & 20.09 \\
\hline BDE17 & - & - & - & - & - & - & - & - & - & - & - & - \\
\hline BDE28 & - & - & - & - & - & - & 0.47 & 0.04 & 56.19 & 5.32 & - & - \\
\hline BDE47 & 0.96 & 0.06 & 15.54 & 5.06 & 34.21 & 1.55 & 0.84 & 0.03 & 55.62 & 4.28 & 43.09 & 18.42 \\
\hline BDE49 & - & - & 14.33 & 4.51 & 16.34 & 0.32 & 1.03 & 0.08 & 51.58 & 6.04 & 36.64 & 9.37 \\
\hline BDE66 & - & - & - & - & - & - & 1.31 & 0.03 & - & - & - & - \\
\hline BDE71 & - & - & 15.51 & 6.85 & 12.42 & 1.92 & 0.55 & 0.05 & 52.33 & 3.98 & 35.63 & 10.85 \\
\hline BDE77 & - & - & - & - & - & - & - & - & - & - & - & - \\
\hline BDE85 & 1.01 & 0.11 & - & - & - & - & 7.24 & 1.31 & - & - & - & - \\
\hline BDE99 & 16.95 & 2.11 & - & - & - & - & 52.71 & 19.63 & - & - & - & - \\
\hline BDE100 & 0.22 & 0.02 & - & - & - & - & 1.55 & 0.73 & - & - & - & - \\
\hline BDE119 & 0.31 & 0.13 & - & - & - & - & 0.73 & 0.25 & - & - & - & - \\
\hline BDE126 & 2.07 & 0.25 & - & - & - & - & 12.77 & 3.88 & - & - & - & - \\
\hline BDE138 & - & - & - & - & - & - & - & - & - & - & - & - \\
\hline BDE153 & - & - & - & - & - & - & - & - & - & - & - & - \\
\hline BDE154 & - & - & - & - & - & - & - & - & - & - & - & - \\
\hline BDE156 & - & - & - & - & - & - & - & - & - & - & - & - \\
\hline BDE183 & - & - & - & - & - & - & - & - & - & - & - & - \\
\hline BDE184 & - & - & - & - & - & - & - & - & - & - & - & - \\
\hline BDE191 & - & - & - & - & - & - & - & - & - & - & - & - \\
\hline BDE196 & - & - & - & - & - & - & - & - & - & - & - & - \\
\hline BDE197 & - & - & 73.82 & 7.26 & - & - & - & - & 245.5 & 10.36 & - & - \\
\hline BDE206 & 12.19 & 2.78 & - & - & - & - & 28.07 & 9.75 & - & - & - & - \\
\hline BDE207 & 8.69 & 1.48 & 359.3 & 58.17 & - & - & 16.81 & 3.19 & 170.3 & 10.06 & - & - \\
\hline BDE209 & 149.5 & 36.92 & 55.59 & 3.56 & - & - & 128.1 & 25.52 & 88.91 & 11.29 & - & - \\
\hline
\end{tabular}

-: not detected.

Table 2 BDE209 and De-BDE metabolites in different tissues on day 1 and day 28 in high dose group (HG) (unit: ng/g wet weight)

\begin{tabular}{|c|c|c|c|c|c|c|c|c|c|c|c|c|}
\hline \multirow[t]{3}{*}{ BDE } & \multicolumn{6}{|c|}{ Day 1} & \multicolumn{6}{|c|}{ Day 28} \\
\hline & \multicolumn{2}{|c|}{ Muscle } & \multicolumn{2}{|c|}{ Liver } & \multicolumn{2}{|c|}{ Blood } & \multicolumn{2}{|c|}{ Muscle } & \multicolumn{2}{|c|}{ Liver } & \multicolumn{2}{|c|}{ Blood } \\
\hline & Mean & SD & Mean & SD & Mean & SD & Mean & SD & Mean & SD & Mean & SD \\
\hline BDE3 & - & - & 11.08 & 0.39 & 41.08 & 27.05 & - & - & 13.55 & 3.23 & 122.9 & 68.68 \\
\hline BDE7 & - & - & 9.35 & 0.35 & 11.17 & 3.69 & - & - & 11.09 & 2.53 & 35.84 & 4.86 \\
\hline BDE15 & - & - & 11.65 & 0.65 & 11.69 & 4.06 & - & - & 14.37 & 3.74 & 71.92 & 9.36 \\
\hline BDE17 & - & - & - & - & - & - & - & - & - & - & - & - \\
\hline BDE28 & - & - & - & - & - & - & 0.65 & 0.12 & - & - & - & - \\
\hline BDE47 & 0.96 & 0.05 & - & - & 15.62 & 9.31 & 1.16 & 0.07 & - & - & 18.63 & 2.55 \\
\hline BDE49 & 0.99 & 0.01 & - & - & 10.08 & 1.37 & 1.25 & 0.01 & - & - & 13.98 & 1.02 \\
\hline BDE66 & 0.83 & 0.16 & - & - & 3.91 & 1.65 & 0.89 & 0.15 & - & - & 15.89 & 13.04 \\
\hline BDE71 & 0.59 & 0.08 & - & - & 7.93 & 1.26 & 1.25 & 0.15 & - & - & 8.33 & 0.52 \\
\hline BDE77 & - & - & - & - & 11.31 & 3.26 & 1.02 & 0.06 & - & - & 54.61 & 61.41 \\
\hline BDE85 & 2.71 & 0.09 & - & - & - & - & 3.39 & 1.73 & - & - & - & - \\
\hline BDE99 & 1.48 & 0.20 & - & - & - & - & 2.15 & 0.89 & - & - & - & - \\
\hline BDE100 & 0.37 & 0.16 & - & - & - & - & 1.83 & 1.28 & - & - & - & - \\
\hline BDE119 & 1.69 & 0.09 & - & - & - & - & 4.04 & 1.49 & - & - & - & - \\
\hline BDE126 & 4.06 & 0.46 & - & - & - & - & 5.59 & 2.79 & - & - & - & - \\
\hline BDE138 & - & - & - & - & - & - & - & - & - & - & - & - \\
\hline BDE153 & - & - & - & - & - & - & - & - & - & - & - & - \\
\hline BDE154 & - & - & - & - & - & - & - & - & - & - & - & - \\
\hline BDE156 & - & - & - & - & - & - & - & - & - & - & - & - \\
\hline BDE183 & - & - & - & - & - & - & - & - & 40.25 & 1.21 & - & - \\
\hline BDE184 & - & - & 105.2 & 5.24 & - & - & - & - & - & - & - & - \\
\hline BDE191 & - & - & - & - & - & - & - & - & - & - & - & - \\
\hline BDE196 & - & - & - & - & - & - & - & - & - & - & - & - \\
\hline BDE197 & - & - & 52.79 & 3.02 & - & - & - & - & - & - & - & - \\
\hline BDE206 & 29.65 & 2.34 & 128.1 & 5.24 & - & - & 11.53 & 1.88 & - & - & - & - \\
\hline BDE207 & 15.86 & 1.65 & 183.3 & 6.32 & - & - & 9.51 & 1.72 & - & - & - & - \\
\hline BDE209 & 796.1 & 38.4 & 228.0 & 5.63 & - & - & 687.1 & 30.98 & 236.4 & 9.26 & - & - \\
\hline
\end{tabular}

-: not detected. 
and hexa-BDEs were observed. On day 28, a total of 19 BDE congeners were detected, including one mono-BDE (BDE3), two di-BDE (BDE17,15), one tri-BDE (BDE28), five tetra-BDE (BDE47, 49, 66, 71, 77), five penta-BDE (BDE85, 99, 100, 119, 126), one hepta-BDE (BDE183), one octa-BDE (BDE197), two nona-BDE (BDE206, 207), and deca-BDE (BDE209). Of all the De-BDEs congeners, the most commonly detected congener was BDE47, which was found in $83.3 \%$ of the samples, followed by BDE49 and BDE 71, which were found in $75 \%$ of the samples. But the concentration level of BDE49 was a little higher than BDE71 in the detected samples. BDE183 and BDE184 had the least detection frequency, with the detection frequencies below $10 \%$. In addition, the highest concentration of the De-BDEs was BDE207, with the range 8.69$359.3 \mathrm{ng} / \mathrm{g}$, followed by BDE197 and BDE206, with the concentration ranging from $52.79-245.5 \mathrm{ng} / \mathrm{g}$ and from $11.53-128.1 \mathrm{ng} / \mathrm{g}$, respectively. The lowest concentration occurred to BDE100, with the concentration range 0.22 $1.83 \mathrm{ng} / \mathrm{g}$.

To sum up, in terms of BDE209, it could be easily found that the highest concentration existed in muscle, followed by liver. The BDE209 levels were: muscle $>$ liver $>$ blood. Regarding the De-BDEs metabolites, both the detected species and total concentration were predominant in liver. In addition, with regard to the total concentrations of De-BDEs metabolites, the contribution of each tissue was liver $>$ blood $>$ muscle. High BDE mainly existed in muscle and liver tissues, whereas low BDE main existed in blood tissue. As for BDE209 itself, its concentration was much higher than the De-BDEs congeners in all samples. The highest contribution accounted for more than $90 \%$ of the whole PBDE mass on day 1 . While on day 28 , the contribution of BDE209 was relatively low.

\subsection{MeO-BDEs metabolites}

Throughout the experiment, no MeO-BDEs were detected in the control group, whereas in the treatment group, some MeO-BDEs metabolites are observed. The specific concentrations of $\mathrm{MeO}-\mathrm{BDE}$ metabolites are summarized in Tables 3 and 4. Among all the eight $\mathrm{MeO}-\mathrm{BDE}$ congeners, a total of seven congeners were detected excluding 5PMBDE99. On day 1, five MeO-BDE congeners were detected, including two tetra-MeO-BDE (5MBDE47, 4PMBDE49) and three penta-MeO-BDEs (5PMBDE100, 4PMBDE101, 4PMBDE103). On day 28, a total of seven MeO-BDE congeners were detected, including four tetra-MeO-BDEs (5MBDE47, 6MBDE47, 4PMBDE49, 2PMBDE68) and three penta-MeO-BDEs (5PMBDE100, 4PMBDE101, 4PMBDE103). Of the observed MeO-BDEs metabolites, the predominant congener was 5MBDE47, which was detectable in all samples, followed by 4PMBDE49, with its detection frequency of $66.7 \%$. The lowest detection rate was for 2PMBDE68, whose detection frequency was $8.3 \%$. With regard to the concentration levels of the MeO-BDE metabolites, the highest concentration of the MeO-BDEs was also 5MBDE47, with the range from 3.31 to $183.8 \mathrm{ng} / \mathrm{g}$. The lowest concentration was 4PMBDE49, ranging from 2.39 to $115.1 \mathrm{ng} / \mathrm{g}$.

Table 3 MeO-BDE metabolites in different tissues on day 1 and day 28 in LG (unit: ng/g wet weight)

\begin{tabular}{|c|c|c|c|c|c|c|c|c|c|c|c|c|}
\hline \multirow[t]{3}{*}{$\mathrm{BDE}$} & \multicolumn{6}{|c|}{ Day 1} & \multicolumn{6}{|c|}{ Day 28} \\
\hline & \multicolumn{2}{|c|}{ Muscle } & \multicolumn{2}{|c|}{ Liver } & \multicolumn{2}{|c|}{ Blood } & \multicolumn{2}{|c|}{ Muscle } & \multicolumn{2}{|c|}{ Liver } & \multicolumn{2}{|c|}{ Blood } \\
\hline & Mean & SD & Mean & SD & Mean & SD & Mean & SD & Mean & SD & Mean & SD \\
\hline 5MBDE47 & 2.91 & 0.44 & 25.01 & 4.42 & 30.63 & 13.05 & 3.04 & 0.37 & 42.34 & 9.19 & 65.61 & 18.79 \\
\hline 6MBDE47 & - & - & - & - & - & - & - & - & - & - & 35.86 & 9.68 \\
\hline 4PMBDE49 & 2.45 & 0.87 & - & - & 39.87 & 23.58 & 2.50 & 0.16 & - & - & 115.1 & 61.18 \\
\hline 2PMBDE68 & - & - & - & - & - & - & - & - & - & - & - & - \\
\hline 5PMBDE99 & - & - & - & - & - & - & - & - & - & - & - & - \\
\hline 5PMBDE100 & - & - & - & - & - & - & 2.71 & 0.67 & - & - & - & - \\
\hline 4PMBDE101 & - & - & - & - & - & - & - & - & - & - & 39.14 & 6.37 \\
\hline 4PMBDE103 & - & - & - & - & 21.13 & 5.68 & 2.36 & 0.12 & - & - & 52.27 & 25.32 \\
\hline
\end{tabular}

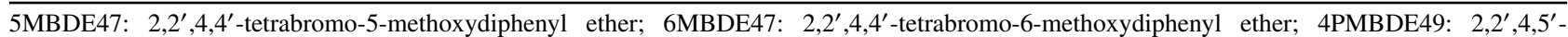

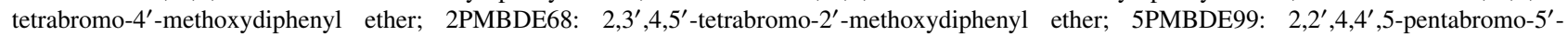

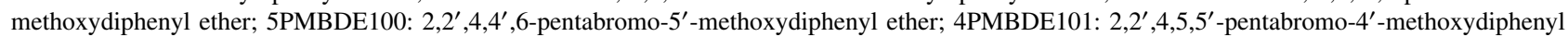
ether; 4PMBDE103: 2,2',4,5', 6-pentabromo-4' -methoxydiphenyl ether.

Table 4 MeO-BDE metabolites in different tissues on day 1 and day 28 in HG (unit: ng/g wet weight)

\begin{tabular}{|c|c|c|c|c|c|c|c|c|c|c|c|c|}
\hline \multirow[t]{3}{*}{$\overline{\mathrm{BDE}}$} & \multicolumn{6}{|c|}{ Day 1} & \multicolumn{6}{|c|}{ Day 28} \\
\hline & \multicolumn{2}{|c|}{ Muscle } & \multicolumn{2}{|c|}{ Liver } & \multicolumn{2}{|c|}{ Blood } & \multicolumn{2}{|c|}{ Muscle } & \multicolumn{2}{|c|}{ Liver } & \multicolumn{2}{|c|}{ Blood } \\
\hline & Mean & SD & Mean & SD & Mean & SD & Mean & SD & Mean & SD & Mean & SD \\
\hline 5MBDE47 & 3.31 & 0.01 & 50.97 & 26.02 & 29.72 & 19.22 & 3.28 & 0.03 & 162.2 & 92.11 & 183.8 & 53.41 \\
\hline 6MBDE47 & - & - & - & - & - & - & - & - & - & - & 24.51 & 1.56 \\
\hline 4PMBDE49 & 2.39 & 0.05 & - & - & 31.67 & 12.61 & 2.54 & 0.24 & - & - & 46.17 & 6.53 \\
\hline 2PMBDE68 & - & - & - & - & - & - & - & - & - & - & 32.47 & 0.24 \\
\hline 5PMBDE99 & - & - & - & - & - & - & - & - & - & - & - & - \\
\hline 5PMBDE100 & - & - & 24.62 & 3.01 & - & - & - & - & 32.19 & 6.12 & 56.14 & 27.70 \\
\hline 4PMBDE101 & - & - & - & - & 19.01 & 1.02 & - & - & - & - & - & - \\
\hline 4PMBDE103 & - & - & - & - & - & - & - & - & - & - & 39.66 & 24.71 \\
\hline
\end{tabular}




\section{Discussion}

\subsection{Tissue distribution of BDE209 and De-BDEs}

Distribution patterns of De-BDEs were analyzed among the muscle, liver and blood within 28-day exposure. Figure 1 presents a comparison of BDE congener contribution observed in muscle, liver and blood on day 1 and day 28 . Clearly, there existed an obvious difference of congener distributions among different fish tissues. With regard to the De-BDEs metabolites, the main De-BDEs metabolites in muscle samples were tri-, tetra-, penta-, nona-BDE, and nona-BDE accounted for the most. Taking the HG for example, after one-day exposure, more than $90 \%$ of the BDE mass contribution in the muscle was BDE209, while nona-BDE congeners comprised $5.32 \%$, penta-BDE congeners comprised $1.21 \%$, tetra-BDE comprised $0.73 \%$. Considering the mean concentrations, the contribution of each congener was nona-BDE $>$ penta-BDE $>$ tetra-BDE. After 28-day exposure, the composition of BDE congener patterns was slightly changed. Tri-BDE was additionally detected compared to the first sampling point (day 1), the contribution sequence of each congener was nona-BDE $>$ penta-BDE $>$ tetra-BDE $>$ tri-BDE. The distribution pattern of De-BDEs in LG was similar to that in HG.

In liver, the observed De-BDEs comprised of mono-, di-, tri-, tetra-, hepta-, octa- and nona-BDE. Nona-BDE was the dominant congener, followed by the hepta- and octa-BDE. There existed some differences of the De-BDEs congeners between LG and HG. On day 1 for LG, mono-, di-, tetra-, octa- and nona-BDE were observed with nona-
BDEs as the predominate congeners, which accounted for approximately $70 \%$ of the total De-BDEs, followed by octa- and tetra- BDEs, accounting for approximately $14 \%$ and $10 \%$, respectively. The contribution of each congener was nona-BDE > octa-BDE > tetra-BDE > di-BDE $>$ mono-BDE. While for $\mathrm{HG}$, the detected DeBDEs contained mono-, di-, hepta-, octa- and nona-BDE. Nona-BDEs were still predominant, which accounted for approximately $62 \%$ of the total De-BDEs, followed by the hepta- and octa- BDEs, accounting for approximately $21 \%$ and $10 \%$, respectively. The contribution of each congener was nona-BDE $>$ hepta-BDE $>$ octa-BDE $>$ di$\mathrm{BDE}>$ mono-BDE. On day 28, some changes occurred to the De-BDE congener patterns. For LG, tri-BDE was additionally observed compared with day 1 with octaBDEs as the predominant congeners, which accounted for approximately $33 \%$ of the total De-BDEss, followed by the nona- and tetra- BDEs, accounting for approximately $23 \%$ and $21 \%$, respectively. The contribution of each congener was octa-BDE $>$ nona-BDE $>$ tetra-BDE $>$ di-BDE $>$ tri$\mathrm{BDE}>$ mono-BDE. For HG, octa- and nona-BDE were not detected compared with day 1, with hepta-BDE as the dominant congener, accounting for about $50 \%$. The congener contribution sequence was hepta-BDE $>$ di-BDE $>$ mono-BDE. The reason for the lack of the octa- and nona- BDE after 28-day exposure was unclear, but it could be due to the increasing metabolism/debromination over time (Hakk and Letcher, 2003).

BDE and metabolites have been widely detected in the blood of fish, birds, rats and humans (Marsh et al.,

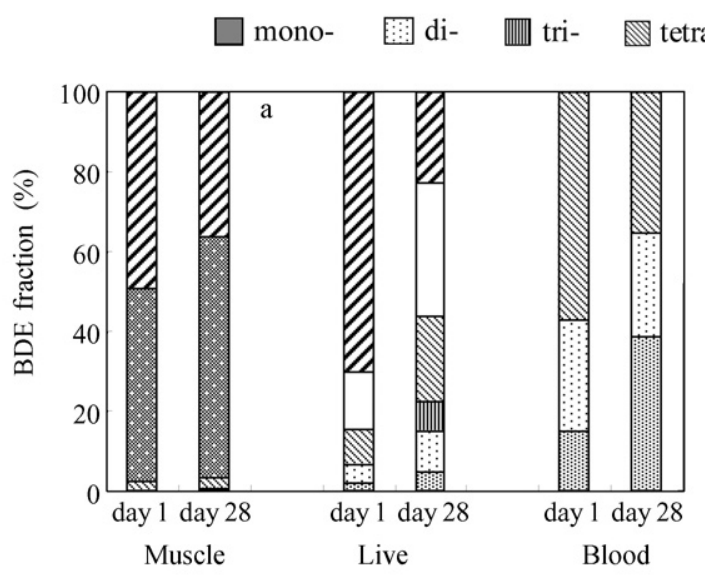

penta- 目 hepta- $\square$ octa- $\square$ nona-
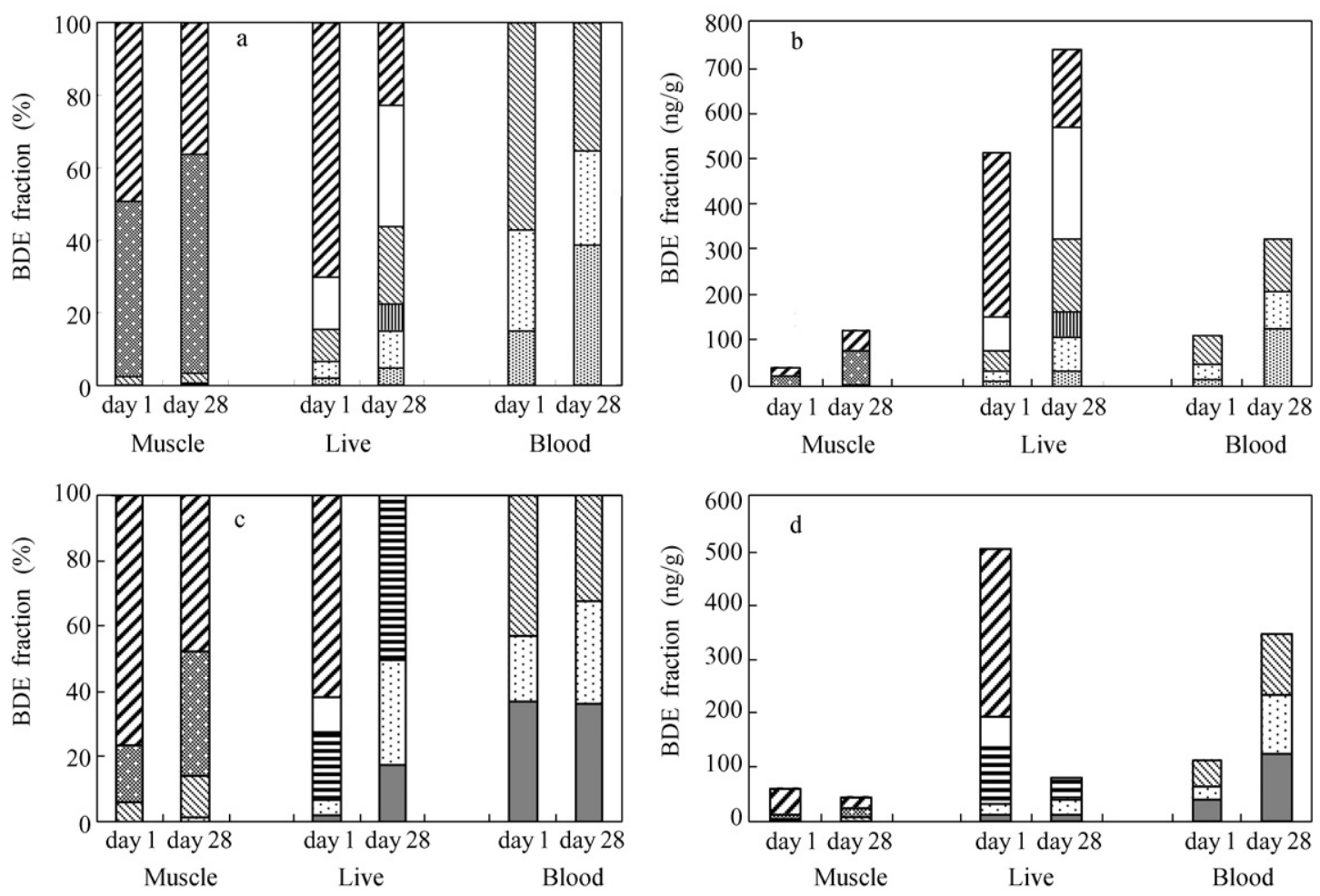

Fig. 1 Percentage contribution of various BDE to total De-BDE and total De-BDE congeners observed in muscle, liver and blood from rainbow trout after 1- and 28-day exposure to BDE209 in low dose (a, b) and high dose groups (c, d). 
2004; Bi et al., 2006; Anderson et al., 2008). In fish, specifically, the BDE metabolites in 13 species plasma have been detected from the Detroit River (Valters et al., 2005). In the present study, only mono-, di-, and tetraBDE were observed. There was no significant difference in BDE congener patterns between the LG and HG. On day 1 , the contribution of each congener was tetra-BDE $>$ di-BDE > mono-BDE for LG. Meanwhile, for HG, the contribution of each congener was tetra-BDE $>$ mono$\mathrm{BDE}>$ di-BDE. On day 28, the contribution of each congener in both groups were mono-BDE $>$ tetra-BDE $>$ di-BDE. In a previous study (Van den Steen et al., 2007), European starlings was exposed to BDE 209 using silastic implants, and then in blood samples, no lower brominated BDE congeners could be detected. The difference of BDE metabolites might easily depend on the exposure route and tested species (Montory and Barra, 2006).

As the liver is a primary tissue for biotransformation of organic compounds, it is reasonable to assume that BDE209 debromination mainly took place in the liver. Microsomal fractions have been used to investigate the biotransformation of organic compounds by fish (Tomy et al., 2004b; McKinney et al., 2006). Consequently, rainbow trout liver microsomes incubated with BDE209 experiment confirmed a metabolic pathway for BDE209 debromination and support the results from the in vivo experiments (Stapleton et al., 2006). From the whole variation trend of the De-BDEs metabolites, lower BDE increased in concentration after 28-day exposure, while higher BDE decreased in concentration. On day 1 , the total concentration in liver was predominant in both LG and HG groups. While on day 28 , the highest concentration occurred to liver in LG and blood in HG. Compared to the previous studies, PBDE congener profiles observed in the rainbow trout were a little different from the results obtained by Kierkegaard et al (1999). In Kierkegaard's study, rainbow trout were fed a diet spiked with the commercial deca-BDE mixture and then hexa- to nona-BDE were found and accumulated with increasing exposure time. In the study conducted by Stapleton et al. (2004), common carp were also exposed to BDE209 through diet. Consequently, one octa-, two heptaand three hexa-BDE congeners were found to increase in concentration during a 60-day dietary experiment. In contrast to these studies, intraperitoneal injection was adopted for exposure pathway in our study, with the presence of mono-, di-, tri-, tetra-, penta-, hepta-, octa- and nona-BDE being detected, whereas hexa-BDE congeners were not observed throughout the whole experiment. The differences suggested that BDE209 metabolism differed in the extent, depending on the fish species and the exposure pathway of the target compound (Law et al., 2008). In the study of Tomy et al. (2004a), lake trout were exposed to different BDE congeners, and the bioaccumulation parameters and biochemical effects were examined, the results also showed that biotransformation and bioaccumulation parameters of BDEs were also specific to this exposure regime and fish species. The debromination of BDE209 by rat also tested that BDE209 metabolism was different depending on species and exposure pathway (Morck et al., 2003).

\subsection{Tissue distribution of MeO-BDE metabolites}

The specific tissue distribution of MeO-BDE metabolites are illustrated in Fig. 2. It could be found that the highest concentration was 5MBDE47, also with the highest detection frequency. The amount of detected species
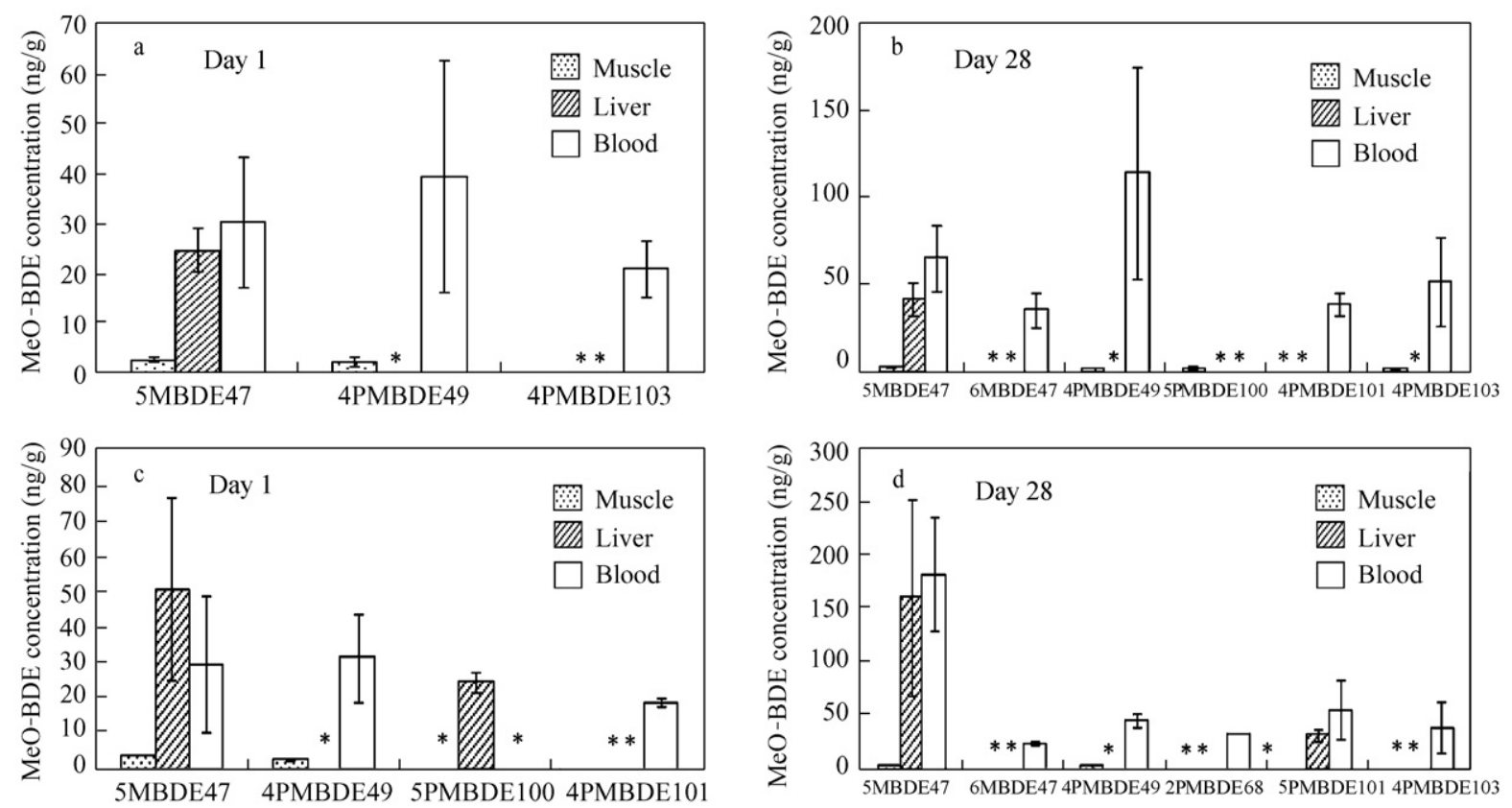

Fig. 2 MeO-BDE congener profiles in different tissues of rainbow trout after 1- and 28- day exposure to BDE209 in low dose (a, b) and high dose groups (c, d). The individual MeO-BDE concentration was the mean values obtained from statistical analysis. * Implies a non-available value. Error bars represent the standard deviations. 
was as follows: blood $>$ muscle $>$ liver. On day 1 , all the detected MeO-BDE metabolites were less, and the concentration was lower. Most MeO-BDE existed in blood. The concentrations in blood and livers were much higher than those in muscle tissue. On day 28, more kinds of MeO-BDEs were observed, especially in blood. All the $\mathrm{MeO}-\mathrm{BDE}$ congeners increased during the exposure period. In muscle this trend was not significant, with the relative percentage deviation (RPD) ranging from $0.91 \%$ to $6.08 \%$. Whereas in liver and blood, the RPD value were much higher than $10 \%$, meaning that the increasing trend was significant from day 1 to day 28 .

Judging from the temporal trends of the total MeO-BDE metabolites (Fig. 3), they all put up an increase trend in the three tissues, the increasing rate sequence: blood $>$ liver $>$ muscle, suggesting that degradation process by methylation more easily took place in blood tissue. In addition, the highest concentration of the total MeO-BDE also occurred in blood, followed by the liver. The accumulation rate and total concentration of MeO-BDE in muscle tissue were lowest. The results observed in the present study indicated that MeO-BDE metabolites could be accumulated in liver and blood, while in muscle, there was no significant change with the lowest MeO-BDE concentration levels. In vitro studies had been carried previously out using liver microsomal fractions (Stapleton et al., 2006), the results showed that rainbow trout could transform as much as $22 \%$ of the BDE 209 mass, the metabolism were mainly driven by liver microsomal fractions, which was supported by in vivo experiments.
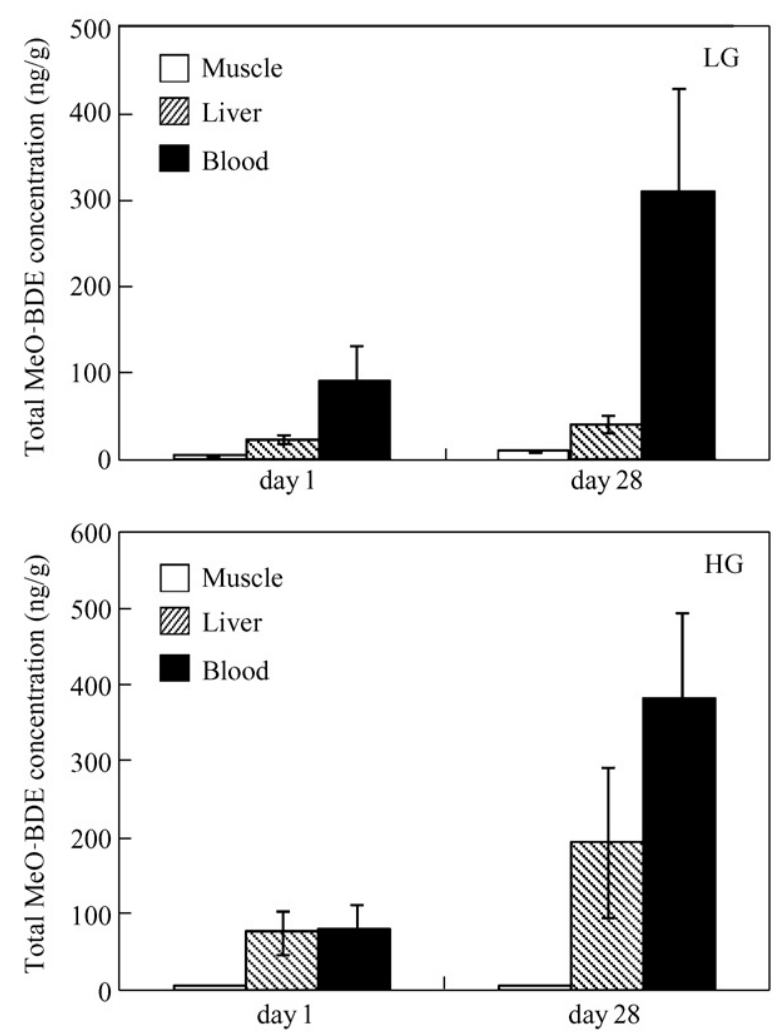

Fig. 3 Time trends of total MeO-BDE in different fish tissues of rainbow trout during the 28-day exposure time.
To summarize, the concentration of MeO-BDE metabolites in blood were highest, also with the most amount of $\mathrm{MeO}-\mathrm{BDE}$ congeners. While in muscle tissues, the MeOBDE were the lowest. From day 1 to day 28, the individual $\mathrm{MeO}-\mathrm{BDE}$ congener level and the total MeO-BDE level all showed an increase trend. That is, the MeO-BDE metabolites accumulated throughout the exposure time, the accumulating rates were: blood $>$ liver $>$ muscle.

\subsection{Comparison of BDE209 metabolism among differ- ent fish tissues}

In different fish tissues, BDE209 could metabolize to De-BDEs and MeO-BDEs. The metabolism patterns were a little different among the fish tissues. In muscle tissue, concentration of BDE 209 was highest, suggesting that BDE209 could accumulate in muscle tissue, and the main metabolites were De-BDEs congeners, with relatively low concentration. Compared with other tissues, the MeOBDE metabolites were less. The main metabolites in liver were also De-BDEs, with the highest values. BDE209 value did not pose an obvious trend during the whole exposure time. While the MeO-BDE metabolites species were the least among the three tissues, but the concentrations were much higher than those in muscle tissue. In blood, the main metabolites of the target compound were MeO-BDEs, and both the total concentration and the total species were the most among the three tissues. The comparisons of BDE metabolites in rainbow trout with other species showed that there was a little difference of BDE metabolites among different species. Such difference might depend on the exposure route and tested species (Montory et al., 2006).

\section{Conclusions}

The rainbow trout were exposed to BDE209 for 28 days by a single intraperitoneal injection. The results from this experiment demonstrated that BDE209 could easily metabolize to De-BDEs and MeO-BDEs. There existed significant differences of De-BDEs and MeOBDEs distribution among different tissues. The De-BDEs metabolites mainly existed in liver, and the MeO-BDE metabolites mainly existed in blood tissue. The specific tissue distribution of BDE and metabolites among muscle, liver and blood samples implies that the degradation rate in blood was the highest, followed by the liver and muscle. Lower De-BDEs metabolites and all the MeO-BDE metabolites showed an increase trend from day 1 to day 28, while higher De-BDEs metabolites showed a decreased trend. More work is needed to determine the pathway by which BDE congeners are metabolized in fish and in other species. And further research should be conducted to thoroughly understand the toxicology of BDE 209 in different species in the food chain.

\section{Acknowledgments}

This work was supported by the National Basic Research Program (973) of China (No. 2009CB421605) and the National Natural Science Foundation of China (No. 20877089, 20737003). 


\section{References}

Anderson H A, Imm P, Knobeloch L, Turyk M, Mathew J, Buelow C et al., 2008. Polybrominated diphenyl ethers (PBDE) in serum: Findings from a US cohort of consumers of sport-caught fish. Chemosphere, 73: 187-194.

Bi X H, Qu W Y, Sheng G Y, Zhang W B, Mai B X, Chen D J et al., 2006. Polybrominated diphenyl ethers in South China maternal and fetal blood and breast milk. Environmental Pollution, 144: 1024-1030.

Chen S J, Gao X J, Mai B X, Chen Z M, Luo X J, Sheng G Y et al., 2006. Polybrominated diphenyl ethers in surface sediments of the Yangtze River Delta: Levels, distribution and potential hydrodynamic influence. Environmental Pollution, 144: 951-957.

de Wit C, 2002. An overview of brominated flame retardants in the environment. Chemosphere, 46: 583-624.

Eljarrat E, Labandeira A, Marsh G, Ralda D, Barcel D, 2007. Decabrominated diphenyl ether in river fish and sediment samples collected downstream an industrial park. Chemosphere, 69: 1278-1286.

Eriksson J, Green N, Marsh G, Bergman A, 2004. Photochemical decomposition of 15 polybrominated diphenyl ether congeners in methanol/water. Environmental Science and Technology, 38: 3119-3125.

Gao Z S, Xu J, Xian Q M, Feng J F, Chen X H, Yu H X, 2009. Polybrominated diphenyl ethers (PBDEs) in aquatic biota from the lower reach of the Yangtze River, East China. Chemosphere,75: 1273-1279.

Gerecke A, Hartmann P, Heeb N, Kohler H, Giger W, Schmid P et al., 2005. Anaerobic degradation of decabromodiphenyl ether. Environmental Science and Technology, 39: 10781083.

Guo Y, Meng X Z, Tang H L, Mai B X, Zeng E, 2008. Distribution of polybrominated diphenyl ethers in fish tissues from the Pearl River delta, China: Levels, compositions, and potential sources. Environmental Toxicology and Chemistry, 27: 576-582.

Haglund P, Zook D, Buser H, Hus J, 1997. Identification and quantification of polybrominated diphenyl ethers and methoxy-polybrominated diphenyl ethers in Baltic biota. Environmental Science and Technology, 31: 3281-3287.

Hakk H, Letcher R, 2003. Metabolism in the toxicokinetics and fate of brominated flame retardants - A review. Environment International, 29: 801-828.

Hardy M L, 2002. The toxicology of the three commercial polybrominated diphenyl oxide (ether) flame retardants. Chemosphere, 46: 757-777.

Hovander L, Athanasiadou M, Asplund L, Jensen S, Wehler E, 2000. Extraction and cleanup methods for analysis of phenolic and neutral organohalogens in plasma. Journal of Analytical Toxicology, 24: 696-703.

Jin J, Liu W Z, Wang Y, Tang X Y, 2008. Levels and distribution of polybrominated diphenyl ethers in plant, shellfish and sediment samples from Laizhou Bay in China. Chemosphere, 71: 1043-1050.

Kierkegaard A, Balk L, Tjarnlund U, De Wit C, Jansson B, 1999. Dietary uptake and biological effects of decabromodiphenyl ether in rainbow trout (Oncorhynchus mykiss). Environmental Science and Technology, 33: 1612-1617.

La Guardia M, Hale R, Harvey E, 2007. Evidence of debromination of decabromodiphenyl ether (BDE209) in biota from a wastewater receiving stream. Environmental Science and Technology, 41: 6663-6670.
Law R, Herzke D, Harrad S, Morris S, Bersuder P, Allchin C, 2008. Levels and trends of HBCD and BDEs in the European and Asian environments, with some information for other BFRs. Chemosphere, 73: 223-241.

Luo Q, Wong M H, Cai Z W, 2007. Determination of polybrominated diphenyl ethers in freshwater fishes from a river polluted by e-wastes. Talanta, 72: 1644-1649.

Marsh G, Athanasiadou M, Bergman A, Asplund L, 2004. Identification of hydroxylated and methoxylated polybrominated diphenyl ethers in Baltic Sea salmon (Salmo salar) blood. Environmental Science and Technology, 38: 10-18.

Mazdai A, Dodder N, Abernathy M, Hites R, Bigsby R, 2003. Polybrominated diphenyl ethers in maternal and fetal blood samples. Environmental Health Perspectives, 111: 12491252.

McKinney M A, De Guise S, Martineau D, Beland P, Arukwe A, Letcher R J, 2006. Biotransformation of polybrominated diphenyl ethers and polychlorinated biphenyls in beluga whale (Delphinapterus leucas) and rat mammalian model using an in vitro hepatic microsomal assay. Aquatic Toxicology, 77: 87-97.

Montory M, Barra R, 2006. Preliminary data on polybrominated diphenyl ethers (PBDEs) in farmed fish tissues (Salmo salar) and fish feed in Southern Chile. Chemosphere, 63: 1252-1260.

Mörck A, Hakk H, Örn U, Wehler E, 2003. Decabromodiphenyl ether in the rat: absorption, distribution, metabolism, and excretion. Drug Metabolism and Disposition, 31: 900-907.

Olsson A, Ceder K, Bergman A, Helander B, 2000. Nestling blood of the white-tailed sea eagle (Haliaeetus albicilla) as an indicator of territorial exposure to organohalogen compounds-an evaluation. Environmental Science and Technology, 34: 2733-2740.

Qiu X H, Mercado-Feliciano M, Bigsby R, Hites R, 2007. Measurement of polybrominated diphenyl ethers and metabolites in mouse plasma after exposure to a commercial pentabromodiphenyl ether mixture. Environmental Health Perspectives, 115: 1052-1058

Shaw S D, Brenner D, Berger M L, Fang F, Hong C S, Addink R et al., 2008. Bioaccumulation of polybrominated diphenyl ethers in harbor seals from the northwest Atlantic. Chemosphere, 73: 1773-1780.

Shi T, Chen S J, Luo X J, Zhang X L, Tang C M, Luo Y et al., 2009. Occurrence of brominated flame retardants other than polybrominated diphenyl ethers in environmental and biota samples from southern China. Chemosphere, 74: 910-916.

Siddiqi M, Laessig R, Reed K, 2003. Polybrominated diphenyl ethers (PBDEs): new pollutants-old diseases. Clinical Medicine and Research, 1: 281-290.

Soderstrom G, Sellstrom U, de Wit C, Tysklind M, 2004. Photolytic debromination of decabromodiphenyl ether (BDE 209). Environmental Science and Technology, 38: 127-132.

Stapleton H, Alaee M, Letcher R, Baker J, 2004a. Debromination of the flame retardant decabromodiphenyl ether by juvenile carp (Cyprinus carpio) following dietary exposure. Environmental Science and Technology, 38: 112-119.

Stapleton H, Brazil B, Holbrook R, Mitchelmore C, Benedict R, Konstantinov A et al., 2006. In vivo and in vitro debromination of decabromodiphenyl ether (BDE 209) by juvenile rainbow trout and common carp. Environmental Science and Technology, 40: 4653-4658.

Stapleton H, Dodder N, Offenberg J, Schantz M, Wise S, 2005. Polybrominated diphenyl ethers in house dust and clothes 
dryer lint. Environmental Science and Technology, 39: 925931.

SFT (Statens forurensningstilsyn), 2009. Ban on deca-BDE. Norwegian Pollution Control Authority (SFT), Oslo, Norway.

Strandberg B, Dodder N, Basu I, Hites R, 2001. Concentrations and spatial variations of polybrominated diphenyl ethers and other organohalogen compounds in Great Lakes air. Environmental Science and Technology, 35: 1078-1083

Tomy G, Palace V, Halldorson T, Braekevelt E, Danell R, Wautier $\mathrm{K}$ et al., 2004a. Bioaccumulation, biotransformation, and biochemical effects of brominated diphenyl ethers in juvenile lake trout (Salvelinus namaycush). Environmental Science and Technology, 38: 1496-1504.

Tomy G, Tittlemier S, Palace V, Budakowski W, Braekevelt E, Brinkworth L et al., 2004b. Biotransformation of $\mathrm{N}$-ethyl perfluorooctanesulfonamide by rainbow trout $(\mathrm{On}$ chorhynchus mykiss) liver microsomes. Environmental Science and Technology, 38: 758-762.
Valters K, Li H, Alaee M, D’Sa I, Marsh G, Bergman A et al., 2005. Polybrominated diphenyl ethers and hydroxylated and methoxylated brominated and chlorinated analogues in the plasma of fish from the Detroit River. Environmental Science and Technology, 39: 5612-5619.

Van den Steen E, Covaci A, Jaspers V, Dauwe T, Voorspoels S, Eens $\mathrm{M}$ et al., 2007. Accumulation, tissue-specific distribution and debromination of decabromodiphenyl ether (BDE 209) in European starlings (Sturnus vulgaris). Environmental Pollution, 148: 648-653.

Vetter W, 2001. A GC/ECNI-MS method for the identification of lipophilic anthropogenic and natural brominated compounds in marine samples. Analytical Chemistry, 73: 4951-4957.

Vetter W, Stoll E, Garson M, Fahey S, Gaus C, Mller J, 2002. Sponge halogenated natural products found at partsper-million levels in marine mammals. Environmental Toxicology and Chemistry, 21: 2014-2019. 